\title{
The Impact of COVID-19 and Government Intervention on Stock Markets of OECD Countries
}

\author{
Haochang Yang ${ }^{1}$, Peidong Deng ${ }^{1}$ \\ 1 Xian Jiaotong University, China \\ Keywords: stock market, government intervention, covid-19 \\ 10.46557/001c.18646
}

\section{Asian Economics Letters}

\begin{abstract}
We study the impact of COVID-19 and various government interventions on the stock market returns of 20 OECD countries from February 1, 2020 to October 1, 2020. We find that stock market returns react significantly negatively to the increase in the number of confirmed cases. The governments' intervention measures, such as social distancing, testing and contact tracing policies, magnify the negative effect of COVID-19 on stock returns. Our findings have important policy implications.
\end{abstract}

\section{Introduction}

The rapid outbreak of COVID-19 has triggered great uncertainty to the global economy, and the panic caused by the uncertainty has also spread among investors, increasing the volatility of the financial market (Iyke, 2020). In response, governments around the world are also actively taking various measures, such as closing schools, restricting entry, virus testing and financial support to control the spread of the pandemic (Phan \& Narayan, 2020). The implementation of government intervention measures will not only control the spread of the pandemic but will also reduce the uncertainty and help restore the global economy. This paper first examines the impact of COVID-19 on stock market returns in OECD countries, and then explores the moderating role of government intervention.

Based on the uncertainty caused by the pandemic, we first assume that the continued spread of the pandemic will have a negative impact on stock market returns. Then we postulate that with the implementation of government intervention measures investor confidence will increase, leading to a positive market response and a possible reduction of the downside economic effects caused by COVID-19.

This note discusses the impact of four comprehensive indicators of government intervention on the stock market, including government response index, containment and health index, economic support index and stringency index. The four comprehensive indicators estimate government intervention policies from different dimensions. For example, the strict index mainly includes measures such as closing schools and restricting travel, while the containment and health index not only covers various control measures, but also considers testing policy and contact tracing (Hale, 2020). Existing research has found that the uncertainty caused by the development of COVID-19 has had a negative effect on global stock market returns (Gil-Alana \& ClaudioQuiroga, 2020; He et al., 2020; Zaremba et al., 2020). The various intervention measures implemented by the government will have different effects on stock returns. For example, various shutdown measures will also have a passive impact on stock returns, while tracking policies will have an energetic effect on stock returns (Ashraf, 2020; Haldar \& Sethi, 2020; Narayan, 2020b).

Based on empirical studies in 20 OECD countries, this paper finds that the emergence of COVID-19 has had a negative impact on the stock market returns. On the other hand, the implementation of various government intervention measures will increase stock market returns. Subsequently, through the analysis of the coefficient of the interaction term between the pandemic and government intervention measures, it is explored whether the negative effect of COVID-19 on stock market returns depends on government intervention measures (Iyke, 2020; Narayan, 2020a; Sharma, 2020).

The main contribution of this paper is to reveal the relationship between COVID-19 and stock market returns.

\section{Data and Methodology}

This paper uses data from February 1, 2020 to October 1, 2020 for 20 OECD countries testing our hypothesis. The data of government intervention measures in 20 OECD countries comes from Our World in Data and the stock market returns data are collected and calculated from the Wind database. Table 1 shows sample information for the 20 OECD countries.

In order to understand the relationship between COVID-19, government intervention (Intervention) and stock market returns (Return), we specify a panel regression model with robust standard errors. In view of the different cultures, circumstance and institution between countries, each regression includes the country-level and time fixed effects.

$$
\begin{aligned}
\text { Return }_{i, t}= & \alpha_{0}+\alpha_{1} \text { Return }_{i, t-1} \\
& +\alpha_{2} \text { COVID }-19_{i, t-1} \\
& +\alpha_{3} X_{i, t}+\mu_{i}+\mu_{t}+\varepsilon_{i, t} \\
\text { Return }_{i, t}= & \alpha_{0}+\alpha_{1} \text { Return }_{i, t-1} \\
& +\alpha_{2}{\text { COVID }-19_{i, t-1}} \\
& +\alpha_{3} \text { Intervention }_{i, t-1}+\alpha_{4} X_{i, t} \\
& +\mu_{i}+\mu_{t}+\varepsilon_{i, t}
\end{aligned}
$$


Table 1: Sample information

\begin{tabular}{|c|c|c|c|}
\hline NO & Code & Country & Stock index \\
\hline 1 & AUS & Australia & S\&P_ASX 200 \\
\hline 2 & AUT & Austria & ATX \\
\hline 3 & BEL & Belgium & BEL 20 \\
\hline 4 & CAN & Canada & S\&P_TSX \\
\hline 5 & $\mathrm{CHE}$ & Switzerland & SMI \\
\hline 6 & DEU & Germany & DAX \\
\hline 7 & DNK & Denmark & OMX Copenhagen 20 \\
\hline 8 & ESP & Spain & IBEX 35 \\
\hline 9 & FRA & France & CAC 40 \\
\hline 10 & GBR & United Kingdom & FTSE 100 \\
\hline 11 & IRL & Ireland & ISEQ Overall \\
\hline 12 & ITA & Italy & FTSE MIB \\
\hline 13 & $J P N$ & Japan & Nikkei 225 \\
\hline 14 & KOR & Korea, South & KOSP 200 \\
\hline 15 & NLD & Netherlands & AEX \\
\hline 16 & NOR & Norway & OSEAX \\
\hline 17 & NZL & New Zealand & NZX 50 \\
\hline 18 & PRT & Portugal & PSI \\
\hline 19 & SWE & Sweden & OMX Stockholm 30 \\
\hline 20 & USA & United States & $S \& P 500$ \\
\hline
\end{tabular}

This table reports the sample countries and the main stock index for each country.

$$
\begin{aligned}
\text { Return }_{i, t}= & \alpha_{0}+\alpha_{1} \text { Return }_{i, t-1} \\
& +\alpha_{2}{\text { COVID }-19_{i, t-1}} \\
& +\alpha_{3} \text { Intervention }_{i, t-1} \\
& +\alpha_{4}\left(\text { COVID }-19_{i, t-1}\right) \\
& \times\left(\text { Intervention }_{i, t}\right)+\alpha_{5} X_{i, t} \\
& +\mu_{i}+\mu_{t}+\varepsilon_{i, t}
\end{aligned}
$$

Following Narayan et al. (2020), since there is a certain inertia factor in stock returns, we capture its persistency with a lagged dependent variable as an explanatory variable. Similarly, the COVID-19 has a certain lag effect on stock returns, so the logarithm of the total number of confirmed cases in each country with a lag of one day was selected as the independent variable. For government intervention independent variables, we used four comprehensive indicators from the OxCGRT database. The variables include stringency index, government response index, containment and health index and economic support index. Finally, $X_{i, t}$ corresponds to a set of other explanatory variables including the logarithm of market value $(\operatorname{Ln}(m v))$ and price-to-earnings ratio $(P E)$.

\section{Empirical results and discussion \\ A. Data description}

Table 2 provides the statistical information on the variables used in this paper. From Table 2, we find that minimum value of stock returns is -0.169 and the maximum value is 0.119 , which shows that the stock returns have changed significantly during the sample period. The minimum values of the stringency index, government response index and containment and health index are all zero, while the maximum values are $96.3,85.42$ and 91.32 , respectively. This statistical result shows that there is a big gap in the intensity of government intervention measures. We infer that in the early stages of the pandemic, governments in various countries generally did not recognize the severity of COVID-19, so the degree of intervention was low. However, with the rapid spread of the pandemic, the degree of government intervention gradually increased.

\section{B. Basic results}

Table 3 presents these regression results of the first equations explained above. It can be seen from the results that the increase in the number of total confirmed cases of COVID-19 has had a significant negative impact on stock market returns. The second to fifth columns illustrate the regression results of the impact of the government's four comprehensive indicators on stock market returns. According to the results, the stringency index, government response index and containment and health index all have a significant and positive effect on stock market returns. However, the statistical regression result of the economic support index is insignificant. According to the above regression results, with the aggravation of COVID-19, the uncertainty of the market is aggravated, leading to investor panic and the loss of confidence in the market, which has a negative effect on stock returns. However, the social distancing, testing and contact tracing policies implemented by the government have had a positive effect on stock returns. The reason for the insignificant regression results of the economic support index may be that the index only reflects the level of income and debt relief support, and does not involve the financial market, so stock returns are not 
Table 2: Descriptive statistics

\begin{tabular}{lccccc}
\hline Variable & Obs. & Mean & Std.Dev. & Min. & Max. \\
\hline Return & 3380 & 0 & .022 & -.169 & .119 \\
Ln(case) & 3228 & 9.634 & 3.063 & 0 & 15.794 \\
Stringency Index & 3380 & 51.439 & 23.34 & 0 & 96.3 \\
Government Response Index & 3380 & 53.238 & 20.124 & 0 & 85.42 \\
Containment \& Health Index & 3380 & 52.195 & 19.736 & 0 & 91.32 \\
Economic Support Index & 3380 & 59.501 & 31.901 & 0 & 100 \\
Ln(mv) & 2873 & 9.391 & 2.694 & 5.332 & 15.943 \\
$P E$ & 3380 & 20.057 & 19.16 & 0 & 291.947 \\
\hline
\end{tabular}

This table has selected descriptive statistics (number of observations (Obs.), mean, standard deviation (Std. Dev.), minimum (Min.) and maximum (Max.) values for stock market returns, $\log$ of COVID-19 cases, the four COVID-19 indices, log of market value $(\operatorname{Ln}(m v))$, and price-earnings ratio $(P E)$ ).

Table 3: Impact of government actions amid COVID-19 on stock market returns

\begin{tabular}{|c|c|c|c|c|c|}
\hline & (1) & (2) & (3) & (4) & (5) \\
\hline \multirow[t]{2}{*}{ Return(-1) } & $-0.111^{* * *}$ & $-0.148^{* * *}$ & $-0.116^{* * *}$ & $-0.142^{* * *}$ & $-0.132^{* * *}$ \\
\hline & $(-2.96)$ & $(-4.58)$ & $(-3.17)$ & $(-4.43)$ & $(-3.30)$ \\
\hline \multirow[t]{2}{*}{$\operatorname{Ln}($ case $)(-1)$} & $-0.001^{* *}$ & $-0.002^{* *}$ & $-0.001^{*}$ & $-0.002^{* * *}$ & -0.001 \\
\hline & $(-2.14)$ & $(-2.81)$ & $(-1.78)$ & $(-3.14)$ & $(-1.37)$ \\
\hline \multirow[t]{2}{*}{ Stringency Index } & & $0.001^{* * *}$ & & & \\
\hline & & $(6.81)$ & & & \\
\hline \multirow[t]{2}{*}{ Government Response Index } & & & $0.001^{* * *}$ & & \\
\hline & & & (4.11) & & \\
\hline \multirow[t]{2}{*}{ Containment \& Health Index } & & & & $0.001^{* * *}$ & \\
\hline & & & & $(5.13)$ & \\
\hline \multirow[t]{2}{*}{ Economic Support Index } & & & & & 0.001 \\
\hline & & & & & $(1.15)$ \\
\hline \multirow[t]{2}{*}{$\operatorname{Ln}(m v)$} & $0.019^{* * *}$ & $0.024^{* * *}$ & $0.025^{* * *}$ & $0.018^{* *}$ & $0.026^{* * *}$ \\
\hline & $(3.32)$ & $(3.15)$ & $(4.24)$ & $(2.26)$ & $(4.49)$ \\
\hline \multirow[t]{2}{*}{$P E$} & -0.001 & -0.001 & -0.001 & -0.001 & -0.000 \\
\hline & $(-0.61)$ & $(-1.33)$ & $(-0.86)$ & $(-1.21)$ & $(-0.29)$ \\
\hline \multirow[t]{2}{*}{ Constant } & $-0.167^{* * *}$ & $-0.213^{* * *}$ & $-0.236^{* * *}$ & $-0.153^{* *}$ & $-0.245^{* * *}$ \\
\hline & $(-3.25)$ & $(-3.20)$ & $(-4.38)$ & $(-2.22)$ & $(-4.48)$ \\
\hline Country & Yes & Yes & Yes & Yes & Yes \\
\hline Time & Yes & Yes & Yes & Yes & Yes \\
\hline Observations & 2,175 & 2,175 & 2,175 & 2,175 & 2,175 \\
\hline$R$-squared & 0.371 & 0.234 & 0.375 & 0.229 & 0.403 \\
\hline
\end{tabular}

This table reports results from the regression models. The $t$-statistics in parentheses are based on robust standard errors and ${ }^{*}, * * * * * *$ denote statistical significance at the $10 \%, 5 \%$, and $1 \%$ levels, respectively.

sensitive to this.

Next, we explore how the interaction between government intervention and COVID-19 affects stock returns. As shown in the Table 4, the interaction term of $\operatorname{Ln}$ (case)*Stringency Index is significantly negative, which indicates that stricter isolation and blockade policies will aggravate the negative effect of COVID-19 on stock market returns. Similarly, the interaction term of $\operatorname{Ln}$ (case) *Government Response Index and Ln(case)*Containment \& Health Index, are both statistically significant and negative, sug- gesting that various government intervention measures have further amplified the negative impact of the pandemic on stock market returns. However, only the interaction term of $\operatorname{Ln}$ (case)*Government Response Index is significantly negative at the $1 \%$ level. This result shows that the government's more dimensional intervention measures will more significantly aggravate the negative effect of the pandemic on stock market returns. The interaction term of Ln(case) ${ }^{*}$ Economic Support Index is still statistically insignificant. 
Table 4: The moderating effect of government actions on stock returns

\begin{tabular}{|c|c|c|c|c|}
\hline & (1) & (2) & (3) & (4) \\
\hline \multirow[t]{2}{*}{ Return(-1) } & $-0.149^{* * *}$ & $-0.146^{* * *}$ & $-0.144^{* * *}$ & $-0.114^{* *}$ \\
\hline & $(-4.58)$ & $(-4.55)$ & $(-4.46)$ & $(-2.19)$ \\
\hline \multirow[t]{2}{*}{$\operatorname{Ln}($ case $)(-1)$} & $-0.002^{* * *}$ & $-0.002^{* * *}$ & $-0.002^{* * *}$ & -0.001 \\
\hline & $(-3.15)$ & $(-3.49)$ & $(-3.21)$ & $(-0.67)$ \\
\hline \multirow[t]{2}{*}{ Stringency Index } & $0.001^{* * *}$ & & & \\
\hline & (3.78) & & & \\
\hline \multirow[t]{2}{*}{$\operatorname{Ln}(\text { case })^{*}$ Stringency Index $(-1)$} & $-0.001^{* *}$ & & & \\
\hline & $(-2.59)$ & & & \\
\hline \multirow[t]{2}{*}{ Government Response Index } & & $0.001^{* * *}$ & & \\
\hline & & $(4.35)$ & & \\
\hline \multirow[t]{2}{*}{$\operatorname{Ln}(\text { case })^{*}$ Government Response Index(-1) } & & $-0.001^{* * *}$ & & \\
\hline & & $(-3.71)$ & & \\
\hline \multirow[t]{2}{*}{ Containment \& Health Index } & & & $0.001^{* * *}$ & \\
\hline & & & $(3.75)$ & \\
\hline \multirow[t]{2}{*}{$\operatorname{Ln}(\text { case })^{*}$ Containment \& Health Index $(-1)$} & & & $-0.001^{* *}$ & \\
\hline & & & $(-2.87)$ & \\
\hline \multirow[t]{2}{*}{ Economic Support Index } & & & & $0.001^{*}$ \\
\hline & & & & $(1.75)$ \\
\hline \multirow[t]{2}{*}{ Ln(case)* Economic Support Index(-1) } & & & & -0.000 \\
\hline & & & & $(-1.67)$ \\
\hline \multirow[t]{2}{*}{$\operatorname{Ln}(m v)$} & $0.026^{* * *}$ & $0.023^{* *}$ & $0.022^{* *}$ & $0.053^{* * *}$ \\
\hline & $(3.23)$ & $(2.51)$ & $(2.42)$ & $(4.59)$ \\
\hline \multirow[t]{2}{*}{$P E$} & -0.001 & -0.001 & -0.001 & 0.000 \\
\hline & $(-0.43)$ & $(-0.33)$ & $(-0.50)$ & $(1.12)$ \\
\hline \multirow[t]{2}{*}{ Constant } & $-0.247^{* * *}$ & $-0.223^{* *}$ & $-0.206^{* *}$ & $-0.512^{* * *}$ \\
\hline & $(-3.39)$ & $(-2.63)$ & $(-2.48)$ & $(-4.60)$ \\
\hline Country & Yes & Yes & Yes & Yes \\
\hline Time & Yes & Yes & Yes & Yes \\
\hline Observations & 2,175 & 2,175 & 2,175 & 2,175 \\
\hline R-squared & 0.236 & 0.233 & 0.232 & 0.480 \\
\hline
\end{tabular}

This table reports results from the regression models. The $t$-statistics in parentheses are based on robust standard errors and $* * * * * * *$ denote statistical significance at the $10 \%, 5 \%$, and $1 \%$ levels, respectively.

Regardless of the regression results in Tables $\underline{3}$ and $\underline{4}$, the lagged one-period regression coefficients of stock returns are significant, which suggest that stock returns do have a certain inertial effect. Therefore, it is reasonable to incorporate the lagged one-period of the dependent variable in the model.

\section{Conclusion}

In this paper, we illustrate the relationship between COVID-19, government intervention and stock market returns. We find that: (a) the gradual increase in the number of confirmed cases of COVID-19 has a negative impact on stock market returns; (b) government intervention measures such as social isolation, testing and contact tracing policies have had a positive effect on stock market returns; and (c) the government's economic support policies did not have a statistically significant impact on stock market returns. Subsequently, through the analysis of the interaction item, it is concluded that the implementation of various government intervention measures will exacerbate the negative effect of COVID-19 on stock returns.

Heyden \& Heyden (2020) and Shanaev et al. (2020) also come to a similar conclusion that the government intervention measures such as social distancing, and containment measures will have a negative impact on financial market earnings. However, the above-mentioned research only reflects the market reaction in the short term. The time span covered in this paper is longer, from February 1 to October 1 , so it can better reflect the counterproductive impact of government intervention on stock market returns. Overall, the spread of COVID-19 has had a devastating impact on the world economy, and as the pandemic in Europe has re-entered a rebound period, research on the impact of government interventions on the economy can better provide reference for future policy design.

Submitted: November 19, 2020 AEDT, Accepted: January 03, 
2021 AEDT

This is an open-access article distributed under the terms of the Creative Commons Attribution 4.0 International License (CCBY-SA-4.0). View this license's legal deed at https://creativecommons.org/licenses/by-sa/4.0 and legal code at https://creativecommons.org/licenses/by-sa/4.0/legalcode for more information. 


\section{REFERENCES}

Ashraf, B. N. (2020). Economic impact of government interventions during the COVID-19 pandemic: International evidence from financial markets. Journal of Behavioral and Experimental Finance, 27, 100371. https://doi.org/10.1016/i.jbef.2020.100371

Gil-Alana, L. A., \& Claudio-Quiroga, G. (2020). The COVID-19 IMPACT on the ASIAN STOCK MARKETS. Asian Economics Letters, 1(2). https://doi.org/10.465 $\underline{57 / 001 c .17656}$

Haldar, A., \& Sethi, N. (2020). The Effect of Countrylevel Factors and Government Intervention on the Incidence of COVID-19. Asian Economics Letters, 1(2). https://doi.org/10.46557/001c.17804

Hale, T. (2020). Variation in government responses to COVID-19. Working paper.

He, P., Sun, Y., Zhang, Y., \& Li, T. (2020). COVID-19's Impact on Stock Prices Across Different Sectors-An Event Study Based on the Chinese Stock Market. Emerging Markets Finance and Trade, 56(10), 2198-2212. https://doi.org/10.1080/1540496x.2020.1 785865

Heyden, K. J., \& Heyden, T. (2020). Market reactions to the arrival and containment of COVID-19: An event study. Available at SSRN 3587497.

Iyke, B. N. (2020). Economic Policy Uncertainty in Times of COVID-19 Pandemic. Asian Economics Letters, 1(2), 17665. https://doi.org/10.46557/001c.17 $\underline{665}$
Narayan, P. K. (2020a). Has COVID-19 Changed Exchange Rate Resistance to Shocks? Asian Economics Letters, 1(1). https://doi.org/10.46557/001 c. 17389

Narayan, P. K. (2020b). Did Bubble Activity Intensify During COVID-19? Asian Economics Letters, 1(2). htt ps://doi.org/10.46557/001c.17654

Narayan, P. K., Phan, D. H. B., \& Liu, G. (2020). COVID-19 lockdowns, stimulus packages, travel bans, and stock returns. Finance Research Letters, 101732. https://doi.org/10.1016/i.frl.2020.101732

Phan, D. H. B., \& Narayan, P. K. (2020). Country responses and the reaction of the stock market to COVID-19-A preliminary exposition. Emerging Markets Finance and Trade, 56(10), 2138-2150. http s://doi.org/10.1080/1540496x.2020.1784719

Shanaev, S., Shuraeva, A., \& Ghimire, B. (2020). The Financial Pandemic: COVID-19 and Policy Interventions on Rational and Irrational Markets. Available at SSRN 3589557.

Sharma, S. S. (2020). A Note on the Asian Market Volatility During the COVID-19 Pandemic. Asian Economics Letters, 1(2). https://doi.org/10.46557/001 c. 17661

Zaremba, A., Kizys, R., Aharon, D. Y., \& Demir, E. (2020). Infected Markets: Novel Coronavirus, Government Interventions, and Stock Return Volatility around the Globe. Finance Research Letters, 35, 101597. https://doi.org/10.1016/i.frl.2020.101597 